\title{
Intraoperative hypothermia during vascular neurosurgical procedures
}

\author{
Raymond Choi, M.Sc., Robert H. Andres, M.D., Gary K. Steinberg, M.D., Ph.D., \\ and Raphael GuZman, M.D.
}

Department of Neurosurgery, Stanford University Medical Center, Stanford, California

\begin{abstract}
Increasing evidence in animal models and clinical trials for stroke, hypoxic encephalopathy for children, and traumatic brain injury have shown that mild hypothermia may attenuate ischemic damage and improve neurological outcome. However, it is less clear if mild intraoperative hypothermia during vascular neurosurgical procedures results in improved outcomes for patients. This review examines the scientific evidence behind hypothermia as a treatment and discusses factors that may be important for the use of this adjuvant technique, including cooling temperature, duration of hypothermia, and rate of rewarming. (DOI: 10.3171/2009.3.FOCUS0927)
\end{abstract}

\section{KEY WoRdS - intraoperative hypothermia - vascular cerebral aneurysm • subarachnoid hemorrhage}

$\mathrm{I}$ $\mathrm{N}$ the $1950 \mathrm{~s}$, hypothermia at $25^{\circ} \mathrm{C}$ or less was used to protect the brain from ischemia during temporary occlusion of blood vessels during cerebral aneurysm surgery. ${ }^{14,43}$ However, this method fell out of favor due to lethal complications such as arrhythmia, ${ }^{34}$ cardiac arrest, bleeding tendency, circulatory inhibition, and high infection rates leading to poor outcomes. ${ }^{14,42,44}$ The publication of a study in 1987 showed a reduction of only $1-2^{\circ} \mathrm{C}$ significantly protected the brain against experimental stroke in rats. ${ }^{8}$ Since then there have been many studies on the mechanisms by which mild $\left(33-36^{\circ} \mathrm{C}\right)$ and moderate $\left(28-32^{\circ} \mathrm{C}\right)$ hypothermia protects the brain from ischemic damage. Here we review the scientific evidence behind the use of hypothermia as a method of attenuating ischemic damage, and the available clinical evidence for the use of intraoperative hypothermia in vascular neurosurgical procedures. We also suggest future studies for this controversial clinical modality.

\section{Scientific Evidence}

A better understanding of the mechanisms of cell death following cerebral ischemia has been necessary to

\footnotetext{
Abbreviations used in this paper: $\mathrm{BBB}=$ blood-brain barrier; DHCA = deep hypothermic circulatory arrest; GOS = Glasgow Outcome Scale; IHAST = Intraoperative Hypothermia for Aneurysm Surgery Trial; $\mathrm{SAH}=$ subarachnoid hemorrhage; TBI = traumatic brain injury.
}

appreciate the way in which hypothermia may protect the brain. When cerebral blood flow is reduced, adenosine triphosphate is depleted and anoxic depolarization and/or spreading depression such as depolarization follows. Glutamate is released from the intracellular to the extracellular space, stimulating $N$-methyl-D-aspartate receptors and leading to increased intracellular calcium levels..$^{10}$ Meanwhile, ischemia/reperfusion causes reactive oxygen species to be produced in large amounts. ${ }^{9}$ These acute processes cause mitochondrial disruption, which coupled with BBB disruption, ultimately lead to necrotic neuronal death. ${ }^{16}$ Furthermore, necrosis is exacerbated by free radicals generated from inflammatory factors such as matrix metalloproteinases, ${ }^{52}$ nuclear transcription factor $\kappa \mathrm{B},{ }^{68}$ and stress-activated mitogen-activated protein kinase. ${ }^{28}$ Apoptosis also occurs after stroke. After stroke, dying cells express proapoptotic proteins of the Bcl-2 family, Bax, Bad, and Bid, ${ }^{22}$ while surviving neurons upregulate antiapoptotic proteins of the Bcl-2 family, Bcl2 , and Bcl-xL. Furthermore, caspase- 9 and -3 activity is stimulated when cytochrome $\mathrm{c}$ is released from the mitochondria into the cytosol, leading to apoptosis. Apoptosis and necrosis probably occur simultaneously and represent overlapping ends of a cell death continuum.

Thus, it is not surprising that a majority of research shows that blocking damaging cascades is an important mechanism underlying hypothermic protection. It has been shown that adenosine triphosphate depletion and anoxic depolarization are delayed or attenuated by intra- 


\section{R. Choi et al.}

ischemic hypothermia. ${ }^{27,60}$ It also maintains the integrity of the BBB, ${ }^{16,31}$ suppresses inflammation, ${ }^{30,64}$ stops glutamate release, ${ }^{7,46}$ attenuates free radical production, ${ }^{38}$ inhibits protein kinase $\mathrm{C}$ translocation, ${ }^{55,56}$ blocks matrix metalloproteinase expression, and inhibits necrosis and apoptosis. In addition, hypothermia attenuates astrocyte activity and inhibits white matter injury. ${ }^{15,32}$ Similarly, postischemic hypothermia prevents BBB permeability, ${ }^{51}$ attenuates inflammation, ${ }^{26}$ inhibits free radical generation, ${ }^{25}$ and suppresses caspase activities. ${ }^{63}$ In fact, almost every damaging cascade related to inflammation and $\mathrm{BBB}$ permeability seems to be inhibited by hypothermia.

Emerging research has also shown that mild and moderate hypothermia not only blocks cell signaling pathways of apoptosis and necrosis, but it also promotes the expression of antiapoptotic and prosurvival genes. Of note, the upregulation of the tumor suppressor gene $p 53$ has also been shown to correlate with neuronal survival. Recent work has also shown that hypothermia selectively regulates certain signals in the PI3K/Akt kinase pathways that promote neuroprotection. ${ }^{66,67}$

Even as these reports have demonstrated the efficacy of hypothermia to protect the rodent brain, it is important to remember that mild and moderate hypothermia does not always lessen ischemic damage. Intra-ischemic hypothermia seems to promote the most neuroprotection for transient ischemia or reperfusion models, while neuroprotection for permanent ischemia models appears to be more variable. Furthermore, mild hypothermia protected the rodent brain only when applied immediately after reperfusion, whereas it failed to protect the brain when applied even after 15 minutes of reperfusion. ${ }^{33}$ Therefore, it appears that the therapeutic time window, coupled with the duration and depth of hypothermia, is likely to be clinically relevant.

\section{Translation Into Clinical Application}

The overwhelming scientific evidence that mild to moderate hypothermia is an effective treatment in experimental models of stroke, neonatal hypoxia, and TBI has paved the way for clinical studies to evaluate the efficacy of this technique as a treatment. Though there is still some debate on the conclusions of studies, $6,13,20,39,54,61$ hypothermia has been implemented for the treatment of head trauma, stroke, and cardiac arrest. Another clinical modality for hypothermia is to use it intraoperatively to prolong the time of temporary occlusion during cerebral aneurysm procedures. Unfortunately little experimental and clinical evidence exist regarding the effectiveness of intraoperative hypothermia to attenuate ischemic damage during cerebral aneurysm procedures. In addition, the balance between oxygen supply and demand systemically and in the brain may worsen during aneurysm surgery. Despite the dearth of available evidence, a British survey showed that $58 \%$ of surgeons who replied (205 of 274) attempted to cool the patient during cerebral aneurysm surgery. ${ }^{47}$ Here we review the clinical evidence and important considerations for the use of intraoperative hypothermia in vascular neurosurgical procedures and suggest future studies for this controversial clinical modality.

\section{Cooling Temperature}

In the 1950s and 1960s, Daw ${ }^{14}$ and Michenfelder ${ }^{43}$ and their colleagues reported the use of hypothermia at $25^{\circ} \mathrm{C}$ for cerebral aneurysm surgery. Neurosurgeons discontinued this method until experimental evidence in the laboratory showed that mild to moderate hypothermia could be beneficial in models of stroke and TBI while minimizing complications. ${ }^{8,11,45}$ Cooling temperature is thus an important factor in considering clinical studies. Most of the clinical studies for intraoperative hypothermia have used between 33 and $35^{\circ} \mathrm{C}$ for hypothermic induction as detailed in Table 1.3,12,19,24,53,61 Early studies first showed that mild intraoperative hypothermia is feasible. ${ }^{3,12}$ Baker et al. ${ }^{3}$ found that mild intraoperative hypothermia does not delay emergence of anesthesia compared with normothermia, although there was more shivering postoperatively in the mild hypothermia group. Hindman et al. ${ }^{24}$ subsequently compared neurological outcomes of patients with and without acute stage of SAH undergoing aneurysm clipping under mild hypothermia $\left(33.5^{\circ} \mathrm{C}\right)$ or normothermia $\left(36.5^{\circ} \mathrm{C}\right)$ and found that there were no suggestions of excess morbidity or mortality. This study also found that among patients with $\mathrm{SAH}$, there was a trend for patients in the hypothermia group to have a lower frequency of neurological deficit at 24 and 72 hours after surgery and more returning home than patients in the normothermia group. This association, however, was not significant because the study was underpowered. ${ }^{24}$ However, the IHAST - a well-matched, modern, prospective, international, multicenter, randomized study of 1001 patients in good grades who had aneurysmal SAH - showed that there was no difference in outcome as assessed using the GOS between the mild intraoperative hypothermic and normothermic groups. ${ }^{61}$ Furthermore, there was a trend toward more bacteremia in the hypothermic group, although there was no difference in meningitis, pneumonia, urinary tract infection, or wound infection rate.

Mild hypothermia is usually used in the context of temporary clipping at the proximal and/or distal parent arteries. Total local circulatory arrest is not always safe or even possible in eloquent anatomical conditions and in large or giant aneurysms. Giant intracranial aneurysms $s^{1,37}$ or complex cerebrovascular lesions ${ }^{21}$ may necessitate the use of DHCA $\left(15-18^{\circ} \mathrm{C}\right)$. Unfortunately there are significant complications associated with this procedure that include postoperative intracranial hematoma, some type of cerebral infarction, cranial nerve morbidity, fatal myocardial infarction, and sepsis. ${ }^{36}$ Despite the significant complications, the use of DHCA has significantly improved the prognosis in patients with large or giant cerebral aneurysms, ${ }^{17,62}$ especially with the advent of the closedchest approach. ${ }^{4,57,58,65} \mathrm{~A}$ recent study with well-selected patients using the most up-to-date anesthetic procedures showed that there was 1 complication related to cardiopulmonary bypass in a group of 12 patients. ${ }^{37}$ Although this method is feasible, carefully weighing the risk/benefit ratio is important due to the significantly higher risk of morbidity and mortality. 
Intraoperative hypothermia during vascular neurosurgical procedures

TABLE 1: Clinical studies using intraoperative hypothermia for vascular neurosurgical procedures*

\begin{tabular}{|c|c|c|c|c|c|c|c|c|}
\hline Authors \& Year & $\begin{array}{l}\text { No. of } \\
\text { Cases }\end{array}$ & $\begin{array}{l}\text { Cooling } \\
\text { Method }\end{array}$ & $\begin{array}{l}\text { Mean Target } \\
\text { Temp }\left({ }^{\circ} \mathrm{C}\right) \dagger\end{array}$ & $\begin{array}{c}\text { Mean } \\
\text { Duration of } \\
\text { Hypothermia } \\
\text { (min) } \dagger\end{array}$ & $\begin{array}{c}\text { Mean } \\
\text { Rewarming } \\
\text { Rate }\left({ }^{\circ} \mathrm{C} / \mathrm{hr}\right) \dagger\end{array}$ & $\begin{array}{l}\text { Mean Rewarm- } \\
\text { ing Temp }\left({ }^{\circ} \mathrm{C}\right) \dagger\end{array}$ & $\begin{array}{c}\% \text { w/ GOS } \\
\text { Score } 1 \text { (FU } \\
\text { duration) }\end{array}$ & $\mathrm{p}$ Value \\
\hline Baker et al., 1994 & 13 & WB & $34.3 \pm 0.4$ & NR & $0.7 \pm 0.6$ & $35.8 \pm 1.0$ & NR & NR \\
\hline $\begin{array}{l}\text { Clifton \& Christensen, } \\
\quad 1992\end{array}$ & 21 & WB & 32.0 & NR & NR & NR & NR & NR \\
\hline Foroohar et al., 2000 & 52 & NR & $35.0 \pm 1$ & NR & NR & NR & NA & NA \\
\hline Grady et al., 2002 & 13 & $\mathrm{DHCA}$ & $15.0 \pm 1.4$ & $24 \pm 11$ & NR & NR & NR & NR \\
\hline Hindman et al., 1999 & 24 & $\mathrm{AC}$ & 33.7 (33.2-34.2) & NR & NR & 35.7 (34.9-36.4) & 71 (3-6 mos) & NS \\
\hline Lawton et al., 1998 & 60 & DHCA & $14.9(12.0-19.6)$ & $22.9(2-72)$ & NR & NR & 45 (6 wks) & NA \\
\hline Levati et al., 2007 & 12 & DHCA & $15.1 \pm 1.1(13.5-17.5)$ & NR & NR & $(36.0-37.0)$ & 75 (6 mos) & NA \\
\hline Sato et al., 2000 & 32 & $A C \& W B$ & 34.0 & NR & $\begin{array}{c}\text { time: } 115 \\
\text { (45-250 min) }\end{array}$ & 36.2 & NR & NR \\
\hline Steinberg et al., 2004 & $\begin{array}{c}92 \text { vs } \\
61\end{array}$ & $\begin{array}{l}\text { WB vs } \\
\text { endo }\end{array}$ & 33 & 274 & 1.88 vs 0.69 & $(35-36)$ & $\begin{array}{l}85 \text { vs } 84 \\
\text { (30 days) }\end{array}$ & NS \\
\hline Todd et al., 2005 & 499 & $A C$ & $33.0(32.5-33.5)$ & $324 \pm 120$ & NR & $36.4 \pm 1.0$ & 66 (3 mos) & NS \\
\hline
\end{tabular}

* AC = air cooling; endo = endovascular cooling; NA = not applicable; NR = not reported; NS = not significant; WB = water blanket.

$\dagger$ Ranges are listed inside the parentheses.

\section{Cooling Time}

Experimental studies have shown that mild hypothermia protected the rodent brain only when applied immediately after reperfusion, whereas it failed to protect the brain when applied even after 15 minutes of reperfusion. ${ }^{33}$ Reaching the target temperature at the time of temporary occlusion during vascular neurosurgery may thus be crucial to improved neurological outcome. In addition, a clinical study showed that there was improved neurological outcome for patients with TBI when hypothermia was applied for 24 hours after injury. ${ }^{39}$ It is therefore likely that the timing of hypothermic application after surgery may be important for vascular neurosurgical procedures. Unfortunately, most of the clinical studies did not report the target hypothermic temperature at the time of clipping or the duration of hypothermia, so it may be difficult to evaluate their conclusions. In the IHAST it was reported that the target temperature was reached before or at the time of clipping. ${ }^{61}$ The cooling time in the IHAST was also limited to the mean operative time of 5-6 hours only, so it is possible that their results could be explained by insufficient cooling time to adequately attenuate ischemic damage.

\section{Rate of Rewarming}

Animals studies on TBI have demonstrated that rapid rewarming can result in poorer outcomes due to enhanced inflammatory response, ${ }^{23}$ decreased axonal microtu- bules, ${ }^{40}$ and increased cerebral metabolic rate. ${ }^{18}$ Likewise, clinical studies on the use of hypothermia for TBI have shown that rapid rewarming in patients with TBI resulted in poorer outcomes compared with slow rewarming ${ }^{41,50}$ due to increased risk of hyperkalemia and imbalances in cerebral blood flow. ${ }^{29,35}$ Unfortunately, most clinical studies on mild intraoperative hypothermia and DHCA did not record the rate of rerewarming, ${ }^{12,19,21,24,37,53}$ and rapid rewarming after surgery is commonly practiced. ${ }^{48}$ Investigators in the IHAST trial rapidly rewarmed their patients after surgery, ${ }^{61}$ which could partially explain their results.

\section{Method of Cooling and Rewarming}

Since the cooling temperature, depth and duration of hypothermia, and rate of rewarming may be important to maximize benefit of mild intraoperative hypothermia, the method of cooling and rewarming must be considered. The current methods to control body temperature intraoperatively include surface cooling/rewarming with water blankets and convection devices, ${ }^{12,19,21,24,37,53}$ DHCA, and a new InnerCool catheter (Cardium Therapeutics) method..$^{59}$ It has been reported that the surface cooling method, especially if combined with rapid infusion of cold intravenous fluids, ${ }^{5,49}$ can achieve a rapid systemic and brain temperature decrease with stable control. However, it is usually difficult to control the rewarming rate with this technique. ${ }^{3}$ Baker et al. ${ }^{3}$ found that it was difficult to control rewarming with water blankets and convection 

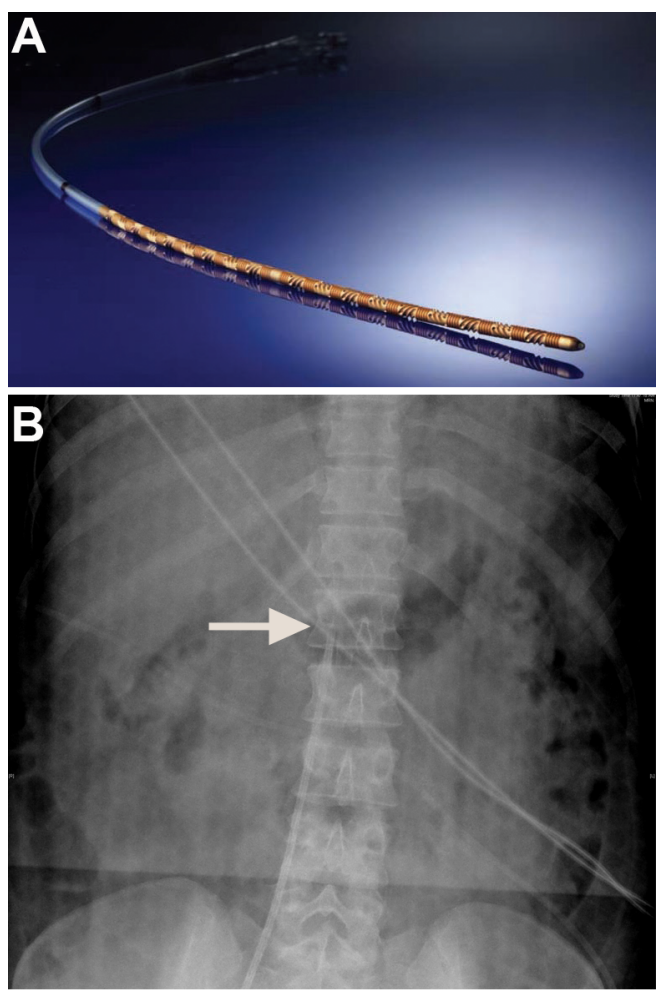

Fig. 1. A: Photograph. The 14-Fr Celsius Control catheter exchanges heat with the body by circulating cool (or warm) saline in a closed-loop manner within the catheter. The catheter is introduced through the femoral vein into the inferior vena cava. (Photo courtesy of InnerCool Therapies, Inc.) B: Radiograph confirming the position of the catheter tip below the diaphragm (arrow).

devices; after surgery patients in the hypothermic group had a body temperature of $35.8 \pm 1.0^{\circ} \mathrm{C}$ and patients in the normothermic group had a body temperature of $37.1 \pm$ $0.5^{\circ} \mathrm{C}$. In our previously published multicenter study, we found that cooling rates in endovascular and surface blanket groups averaged 4.77 and $0.87^{\circ} \mathrm{C} /$ hour, respectively ( $\mathrm{p}$ $<0.001)$. Most importantly at the time of temporary arterial or aneurysm clip placement, $99 \%$ of the endovascular group and $20 \%$ of the surface blanket group had reached the target of $33^{\circ} \mathrm{C}(\mathrm{p}<0.001)$. Also the rewarming rates were significantly faster for the endovascular technique $\left(1.88\right.$ vs $0.69^{\circ} \mathrm{C} /$ hour, $\left.\mathrm{p}<0.001\right)$ leading to near normothermia in $>80 \%$ of cases at the end of the procedure. There had been no clinically significant catheter-related thrombotic, bleeding, or infectious complications in the endovascular group.

We now use the endovascular cooling method with the InnerCool catheter in all cerebrovascular procedures with potential temporary vessel occlusion (Fig. 1). To initiate cooling with the InnerCool system, the catheter is inserted in the operating room after induction of general anesthesia via a standard introducer sheath into the femoral vein. The catheter is advanced to the inferior vena cava until the distal tip of the catheter is just below the right atrium. Correct catheter placement is confirmed using portable fluoroscopy. The desired target temperature is set with the console control panel, and the cooling mode is activated. The rate of cooling is $5.0 \pm 0.5^{\circ} \mathrm{C} /$ hour.
As soon as the hypothermic target temperature of $34^{\circ} \mathrm{C}$ is reached, the Celsius Control system automatically begins to turn off and on intermittently as needed to maintain the patient at target temperature. To initiate active rewarming near the end of surgery, the target temperature is reset to normothermia via the console control panel. To initiate rewarming at a rate of $2.2 \pm 0.2^{\circ} \mathrm{C}$, the Celsius Control system circulates warm saline through the catheter to rewarm the blood as it circulated near the catheter. The catheter is removed at the end of surgery. As soon as the femoral sheath is removed, direct pressure is applied to the femoral access site until hemostasis is achieved.

\section{The IHAST}

The IHAST is the most thorough clinical evaluation of mild intraoperative hypothermia as a method to attenuate ischemic damage during vascular neurosurgical procedures. This study showed that there was no significant difference in neurological outcome between the mild hypothermic and normothermic group ${ }^{61}$ and a long-term follow-up in a smaller subgroup (163 patients) also noted no significant differences between mild intraoperative hypothermic and normothermic group at 9 or 15 months. ${ }^{2}$ However, it is possible that the results could be explained by insufficient cooling time and rapid rewarming. The assumption was that enrollment of 1000 patients would permit detection of a $10 \%$ absolute and $15 \%$ relative improvement in the fraction of patients with a good outcome, as defined by a score of 1 on the GOS. The study, however, only reached a $3.2 \%$ absolute and $5.0 \%$ relative increase in the fraction of patients in the hypothermia group with GOS scores of 1 . Although the study design, sample size, adjudicated outcomes, compliance, and near-perfect follow-up make these results seem robust, even with 1001 good-grade patients the study appears underpowered. A possible explanation is that this study was performed in patients at low risk for ischemic injury, whereas high-risk patients would be more likely to benefit from mild intraoperative hypothermia. In addition, the GOS is a relatively crude measurement of cognitive function and may not detect subtle changes. Finally, subgroup analysis of the data showed that male patients and patients undergoing surgery 8-14 days after SAH had improved neurological outcomes, so it is possible that some patients at low risk for ischemic damage may benefit slightly from mild intraoperative hypothermia.

\section{Future Studies}

Although it is safe to use mild intraoperative hypothermia during vascular neurosurgical procedures, it remains controversial whether this method results in improved neurological outcome. Even though the multicenter trial failed to reach the targeted end point, the data were suggestive of a clinical benefit with hypothermia. Endovascular cooling appears to be a superior technique with minimum temperature fluctuations and faster cooling and rewarming times, when compared with the current method of using water blankets and convection devices. ${ }^{59}$ In future studies a more stringent selection of high-risk 


\section{Intraoperative hypothermia during vascular neurosurgical procedures}

patients and more precise imaging and clinical outcome measures will be needed. Possible intraoperative measurements (for instance, using microdialysis to monitor metabolite changes during hypothermia) will further help to understand the clinical relevance of this technique.

\section{Conclusions}

There is ample evidence from preclinical studies that hypothermia leads to blockage of damaging cascades and is protective against brain ischemic injury. In the experimental and clinical settings it appears that the therapeutic time window, coupled with the duration and depth of hypothermia are likely to be key factors determining the success of this method. The literature demonstrates that although it is apparently safe to use mild intraoperative hypothermia during vascular neurosurgical procedures, it remains a controversial method until further studies are performed.

\section{Disclaimer}

The authors report no conflict of interest concerning the materials or methods used in this study or the findings specified in this paper.

\section{References}

1. Aebert H, Brawanski A, Philipp A, et al: Deep hypothermia and circulatory arrest for surgery of complex intracranial aneurysms. Eur J Cardiothorac Surg 13:223-229, 1998

2. Anderson SW, Todd MM, Hindman BJ, et al: Effects of intraoperative hypothermia on neuropsychological outcomes after intracranial aneurysm surgery. Ann Neurol 60:518-527, 2006

3. Baker KZ, Young WL, Stone JG, et al: Deliberate mild intraoperative hypothermia for craniotomy. Anesthesiology 81:361-367, 1994

4. Baumgartner WA, Silverberg GD, Ream AK, et al: Reappraisal of cardiopulmonary bypass with deep hypothermia and circulatory arrest for complex neurosurgical operations. Surgery 94:242-249, 1983

5. Bernard S, Buist M, Monteiro O, et al: Induced hypothermia using large volume, ice-cold intravenous fluid in comatose survivors of out-of-hospital cardiac arrest: a preliminary report. Resuscitation 56:9-13, 2003

6. Bernard SA, Gray TW, Buist MD, et al: Treatment of comatose survivors of out-of-hospital cardiac arrest with induced hypothermia. N Engl J Med 346:557-563, 2002

7. Busto R, Dietrich WD, Globus MY, et al: Postischemic moderate hypothermia inhibits CA1 hippocampal ischemic neuronal injury. Neurosci Lett 101:299-304, 1989

8. Busto R, Dietrich WD, Globus MY, et al: Small differences in intraischemic brain temperature critically determine the extent of ischemic neuronal injury. J Cereb Blood Flow Metab 7:729-738, 1987

9. Chan PH: Reactive oxygen radicals in signaling and damage in the ischemic brain. J Cereb Blood Flow Metab 21:2-14, 2001

10. Choi DW, Rothman SM: The role of glutamate neurotoxicity in hypoxic-ischemic neuronal death. Annu Rev Neurosci 13:171-182, 1990

11. Clifton GL: Systemic hypothermia in treatment of severe brain injury. J Neurosurg Anesthesiol 7:152-156, 1995

12. Clifton GL, Christensen ML: Use of moderate hypothermia during elective craniotomy. Tex Med 88:66-69, 1992
13. Clifton GL, Miller ER, Choi SC, et al: Lack of effect of induction of hypothermia after acute brain injury. N Engl J Med 344:556-563, 2001

14. Daw EF, Moffitt EA, Michenfelder JD, et al: Profound hypothermia. Can Anaesth Soc J 11:382-393, 1964

15. Dempsey RJ, Combs DJ, Maley ME, et al: Moderate hypothermia reduces postischemic edema development and leukotriene production. Neurosurgery 21:177-181, 1987

16. Dietrich WD, Busto R, Halley M, et al: The importance of brain temperature in alterations of the blood-brain barrier following cerebral ischemia. J Neuropathol Exp Neurol 49:486-497, 1990

17. Drake CG, Barr HW, Coles JC, et al: The use of extracorporeal circulation and profound hypothermia in the treatment of ruptured intracranial aneurysm. J Neurosurg 21:575-581, 1964

18. Enomoto S, Hindman BJ, Dexter F, et al: Rapid rewarming causes an increase in the cerebral metabolic rate for oxygen that is temporarily unmatched by cerebral blood flow. A study during cardiopulmonary bypass in rabbits. Anesthesiology 84:1392-1400, 1996

19. Foroohar M, Macdonald RL, Roth S, et al: Intraoperative variables and early outcome after aneurysm surgery. Surg Neurol 54:304-315, 2000

20. Gluckman PD, Gunn AJ, Wyatt JS: Hypothermia for neonates with hypoxic-ischemic encephalopathy. N Engl J Med 354:1643-1645, 2006

21. Grady RE, Oliver WC Jr, Abel MD, et al: Aprotinin and deep hypothermic cardiopulmonary bypass with or without circulatory arrest for craniotomy. J Neurosurg Anesthesiol 14:137-140, 2002

22. Graham SH, Chen J: Programmed cell death in cerebral ischemia. J Cereb Blood Flow Metab 21:99-109, 2001

23. Hildebrand F, van Griensven M, Giannoudis P, et al: Effects of hypothermia and re-warming on the inflammatory response in a murine multiple hit model of trauma. Cytokine 31:382393, 2005

24. Hindman BJ, Todd MM, Gelb AW, et al: Mild hypothermia as a protective therapy during intracranial aneurysm surgery: a randomized prospective pilot trial. Neurosurgery 44:23-32, 1999

25. Horiguchi T, Shimizu K, Ogino M, et al: Postischemic hypothermia inhibits the generation of hydroxyl radical following transient forebrain ischemia in rats. J Neurotrauma 20:511520,2003

26. Horstmann S, Kalb P, Koziol J, et al: Profiles of matrix metalloproteinases, their inhibitors, and laminin in stroke patients: influence of different therapies. Stroke 34:2165-2170, 2003

27. Ibayashi S, Takano K, Ooboshi H, et al: Effect of selective brain hypothermia on regional cerebral blood flow and tissue metabolism using brain thermo-regulator in spontaneously hypertensive rats. Neurochem Res 25:369-375, 2000

28. Kaminska B: MAPK signalling pathways as molecular targets for anti-inflammatory therapy-from molecular mechanisms to therapeutic benefits. Biochim Biophys Acta 1754:253262,2005

29. Kawahara F, Kadoi Y, Saito S, et al: Slow rewarming improves jugular venous oxygen saturation during rewarming. Acta Anaesthesiol Scand 47:419-424, 2003

30. Kawai N, Nakamura T, Okauchi M, et al: Effects of hypothermia on intracranial hemodynamics and ischemic brain damage-studies in the rat acute subdural hematoma model. Acta Neurochir Suppl (Wien) 76:529-533, 2000

31. Kawanishi M: Effect of hypothermia on brain edema formation following intracerebral hemorrhage in rats. Acta Neurochir Suppl (Wien) 86:453-456, 2003

32. Kimura T, Sako K, Tanaka K, et al: Effect of mild hypothermia on energy state recovery following transient forebrain ischemia in the gerbil. Exp Brain Res 145:83-90, 2002

33. Kuboyama K, Safar P, Radovsky A, et al: Delay in cooling 


\section{R. Choi et al.}

negates the beneficial effect of mild resuscitative cerebral hypothermia after cardiac arrest in dogs: a prospective, randomized study. Crit Care Med 21:1348-1358, 1993

34. Kwak R, Okudaira Y, Suzuki J, et al: [Problems in hypothermic anesthesia for direct surgical treatment of intracranial aneurysms, with special reference to ventricular fibrillation.] No To Shinkei 24:403-410, 1972 (Jpn)

35. Lavinio A, Timofeev I, Nortje J, et al: Cerebrovascular reactivity during hypothermia and rewarming. Br J Anaesth 99:237-244, 2007

36. Lawton MT, Raudzens PA, Zabramski JM, et al: Hypothermic circulatory arrest in neurovascular surgery: evolving indications and predictors of patient outcome. Neurosurgery 43:10-11, 1998

37. Levati A, Tommasino C, Moretti MP, et al: Giant intracranial aneurysms treated with deep hypothermia and circulatory arrest. J Neurosurg Anesthesiol 19:25-30, 2007

38. Maier CM, Sun GH, Cheng D, et al: Effects of mild hypothermia on superoxide anion production, superoxide dismutase expression, and activity following transient focal cerebral ischemia. Neurobiol Dis 11:28-42, 2002

39. Marion DW, Penrod LE, Kelsey SF, et al: Treatment of traumatic brain injury with moderate hypothermia. $\mathbf{N}$ Engl J Med 336:540-546, 1997

40. Maxwell WL, Watson A, Queen R, et al: Slow, medium, or fast re-warming following post-traumatic hypothermia therapy? An ultrastructural perspective. J Neurotrauma 22:873-884, 2005

41. McIntyre LA, Fergusson DA, Hebert PC, et al: Prolonged therapeutic hypothermia after traumatic brain injury in adults: a systematic review. JAMA 289:2992-2999, 2003

42. Michenfelder JD, Milde JH: The effect of profound levels of hypothermia (below 14 degrees $\mathrm{C}$ ) on canine cerebral metabolism. J Cereb Blood Flow Metab 12:877-880, 1992

43. Michenfelder JD, Terry HR Jr, Daw EF, et al: Induced hypothermia: physiologic effects, indications and techniques. Surg Clin North Am 45:889-898, 1965

44. Michenfelder JD, Theye RA: Hypothermia: effect on canine brain and whole-body metabolism. Anesthesiology 29:11071112,1968

45. Milde LN: Clinical use of mild hypothermia for brain protection: a dream revisited. J Neurosurg Anesthesiol 4:211-215, 1992

46. Patel PM, Drummond JC, Cole DJ, et al: Differential temperature sensitivity of ischemia-induced glutamate release and eicosanoid production in rats. Brain Res 650:205-211, 1994

47. Pemberton PL, Dinsmore J: The use of hypothermia as a method of neuroprotection during neurosurgical procedures and after traumatic brain injury: a survey of clinical practice in Great Britain and Ireland. Anaesthesia 58:370-373, 2003

48. Polderman KH: Induced hypothermia and fever control for prevention and treatment of neurological injuries. Lancet 371:1955-1969, 2008

49. Polderman KH, Rijnsburger ER, Peerdeman SM, et al: Induction of hypothermia in patients with various types of neurologic injury with use of large volumes of ice-cold intravenous fluid. Crit Care Med 33:2744-2751, 2005

50. Polderman KH, van Zanten AR, Nipshagen MD, et al: Induced hypothermia in traumatic brain injury: effective if properly employed. Crit Care Med 32:313-314, 2004

51. Preston E, Webster J: A two-hour window for hypothermic modulation of early events that impact delayed opening of the rat blood-brain barrier after ischemia. Acta Neuropathol 108:406-412, 2004
52. Rosenberg GA: Matrix metalloproteinases in neuroinflammation. Glia 39:279-291, 2002

53. Sato K, Sato K, Yoshimoto T: Systemic and cerebral haemodynamics during craniotomy under mild hypothermia in patients with acute subarachnoid haemorrhage. Acta Neurochir (Wien) 142:1013-1020, 2000

54. Shankaran S, Laptook AR, Ehrenkranz RA, et al: Wholebody hypothermia for neonates with hypoxic-ischemic encephalopathy. N Engl J Med 353:1574-1584, 2005

55. Shimohata T, Zhao H, Steinberg GK: Epsilon PKC may contribute to the protective effect of hypothermia in a rat focal cerebral ischemia model. Stroke 38:375-380, 2007

56. Shimohata T, Zhao H, Sung JH, et al: Suppression of deltaP$\mathrm{KC}$ activation after focal cerebral ischemia contributes to the protective effect of hypothermia. J Cereb Blood Flow Metab 27:1463-1475, 2007

57. Silverberg GD, Reitz BA, Ream AK: Hypothermia and cardiac arrest in the treatment of giant aneurysms of the cerebral circulation and hemangioblastoma of the medulla. J Neurosurg 55:337-346, 1981

58. Spetzler RF, Hadley MN, Rigamonti D, et al: Aneurysms of the basilar artery treated with circulatory arrest, hypothermia, and barbiturate cerebral protection. J Neurosurg 68:868-879, 1988

59. Steinberg GK, Ogilvy CS, Shuer LM, et al: Comparison of endovascular and surface cooling during unruptured cerebral aneurysm repair. Neurosurgery 55:307-314, 2004

60. Sutton LN, Clark BJ, Norwood CR, et al: Global cerebral ischemia in piglets under conditions of mild and deep hypothermia. Stroke 22:1567-1573, 1991

61. Todd MM, Hindman BJ, Clarke WR, et al: Mild intraoperative hypothermia during surgery for intracranial aneurysm. $\mathbf{N}$ Engl J Med 352:135-145, 2005

62. Uihlein A, MacCarty CS, Michenfelder JD, et al: Deep hypothermia and surgical treatment of intracranial aneurysms. A five-year survey. JAMA 195:639-641, 1966

63. Van Hemelrijck A, Vermijlen D, Hachimi-Idrissi S, et al: Effect of resuscitative mild hypothermia on glutamate and dopamine release, apoptosis and ischaemic brain damage in the endothelin-1 rat model for focal cerebral ischaemia. J Neurochem 87:66-75, 2003

64. Wang GJ, Deng HY, Maier CM, et al: Mild hypothermia reduces ICAM-1 expression, neutrophil infiltration and microglia/monocyte accumulation following experimental stroke. Neuroscience 114:1081-1090, 2002

65. Young WL, Lawton MT, Gupta DK, et al: Anesthetic management of deep hypothermic circulatory arrest for cerebral aneurysm clipping. Anesthesiology 96:497-503, 2002

66. Zhao H, Sapolsky RM, Steinberg GK: Phosphoinositide-3-kinase/akt survival signal pathways are implicated in neuronal survival after stroke. Mol Neurobiol 34:249-270, 2006

67. Zhao H, Shimohata T, Wang JQ, et al: Akt contributes to neuroprotection by hypothermia against cerebral ischemia in rats. J Neurosci 25:9794-9806, 2005

68. Zheng Z, Yenari MA: Post-ischemic inflammation: molecular mechanisms and therapeutic implications. Neurol Res 26:884-892, 2004

Manuscript submitted January 15, 2009.

Accepted March 6, 2009.

Address correspondence to: Raphael Guzman, M.D., Department of Neurosurgery, Stanford University, 300 Pasteur Drive, R211, Stanford, California 94305-5327. email: raphaelg@stanford.edu. 